\title{
LA SEPULTURA EN EL MARCO DE LOS DERECHOS HUMANOS. UN ANÁLISIS DESDE SU CONTEXTUALIZACIÓN EN EL DERECHO IBEROAMERICANO
}

Burial within the framework of human rights. An analysis from its contextualization in Ibero-American law

ERICK ORTEGA GARCÍA

Departamento Jurídico de la Dirección Provincial de la Vivienda de La Habana (Cuba)

erick@oc.dpvhab.cu

GRETHEL ARIAS GAYOSO

Universidad de Oriente (Cuba)

garias@uo.edu.cu

Cómo citar/Citation

Ortega García, E. y Arias Gayoso, G. (2020).

La sepultura en el marco de los derechos humanos. Un análisis desde su contextualización en el derecho iberoamericano. Anuario Iberoamericano de Justicia Constitucional, 24(2), 365-391. doi: https://doi.org/10.18042/cepc/aijc.24.11

\section{Resumen}

Las prácticas sociales y costumbres determinan la presencia y relación con la muerte. Emerge, así, la necesidad de asegurarse qué tratamiento ha de efectuarse sobre los restos físicos propios. En este contexto, existe ambivalencia de la legitimidad para disponer sobre su propio cadáver. Las normas del derecho público ponderan su tratamiento solo en defensa de la colectividad por cuestiones de salubridad. Es entonces que se enarbola la prominencia de un derecho inalienable al ser humano: el derecho a la sepultura, o derecho del hombre sobre su cadáver. Aunque carece de reconocimiento en los textos constitucionales estudiados, esta ausencia se intenta suplir con leyes sobre cadáveres, cementerios y sanitarias. Sin embargo, por la falta de una ordenación común, no guardan unicidad. 


\title{
Palabras claves
}

Muerte; sepultura; cadáveres; derechos humanos; dignidad humana.

\begin{abstract}
The social practices and customs determine the presence and relationship with the death. It emerges this way, the necessity to make sure what treatment it must make on the physical remains. In this context, ambivalence of the genuineness exists to prepare on its own bones. The norms of the public right only ponder their treatment in defense of the collective for health questions It is then that the prominence is enunciated from an inalienable right to the human being: the right to the sepulcher, or the man's right on their remains. Although it lacks recognition in the studied constitutional texts, this absence is tried to replace with laws it has more than enough cadavers, cemeteries and sanitary. However, for the lack of a common ordination, they don't keep unit.
\end{abstract}

\section{Keywords}

Death; sepulcher; cadavers; human rights; human dignity. 


\section{SUMARIO}

I. INTRODUCCIÓN. II. DESARROLLO: 1. Implicaciones sociales y jurídicas de la muerte. Bases para la disquisición del derecho a la sepultura. 2. La concepción teórica de los derechos humanos y su clasificación. El marco propicio de inserción al derecho a la sepultura: 2.1. La clasificación de los derechos humanos. 2.2. La tutela a la dignidad humana y la normatividad del derecho sobre el cadáver. 2.3. Naturaleza jurídica de los derechos humanos. 3. Concepto de derecho a la sepultura a partir de las categorías que lo integran. Su naturaleza jurídica: 3. 1. Naturaleza jurídica del derecho a la sepultura. 4. Límites y contenido del derecho a la sepultura. Bases para su construcción teórica: 4.1. El derecho sobre el cadáver en el contexto normativo internacional. 5. Conclusiones. Bibliografía. Legislación consultada. Sentencias consultadas.

\section{INTRODUCCIÓN}

La muerte, como proceso terminal de los seres humanos, concluye con la existencia biológica. Incomprendida del todo en su conjunto, existen discrepancias científicas desde el punto de vista termodinámico y neurológico. En suma, es inexistente la definición científica del comienzo en el proceso en que se pasa de la vida a la muerte. La concepción de la muerte en cualquiera de sus ámbitos, ya sea como fin o tránsito, actúa como condicionante para la actuación de los individuos en un sentido u otro ${ }^{1}$.

Se ha discutido el tema de si los restos mortales pueden constituir cosas en el sentido jurídico, o si trascienden como residuo de la personalidad. Se pondera que los restos mortales no pueden constituir cosas, por su inexistente valor económico o patrimonial. No obstante, determinadas partes del cadáver ${ }^{2}$ pueden ser utilizadas para la salvación o cura de enfermedades de otras personas. En estos casos, las partes del cuerpo adquieren un valor relevante para la salud y para la existencia del hombre, convirtiéndose en bienes ${ }^{3}$.

1 En ambientes médicos resulta difícil precisar el momento en que ocurre la muerte, así como las manifestaciones o ausencias que permiten aseverar que una persona está biológicamente muerta. Algunas posturas sostienen el criterio de determinación en la sensibilidad o racionalidad del paciente por medio de las diversas definiciones de «muerte cortical» y «muerte neocortical», Meléndez (2005: 60-68), García (1999: 40), Serani (1999: 37).

2 El término "cadáver» proviene de tres raíces latinas: cara, data y vernis, que significan en conjunto "carne entregada a los gusanos», Díez-Díaz (1983: 42).

$3 \mathrm{Al}$ respecto se abordan criterios doctrinales que tratan de enmarcar al cadáver dentro del caudal hereditario del fallecido, en razón de que quien se beneficie de los bienes, 
De igual forma, se advierte ambivalencia en el reconocimiento pleno de la legitimidad de las personas para disponer sobre su propio cadáver. Se corre el riesgo de que, ante la poca trascendencia que para el derecho privado poseen los restos mortales y su protección, queden en terreno de nadie. Las normas del derecho público ponderan su tratamiento solo en razón de la defensa de la colectividad por cuestiones de salubridad.

Es entonces el testamento el documento idóneo para que los sujetos manifiesten públicamente la finalidad o destino que pretendan sobre sus restos mortales. En ratificación o ausencia de este, se enarbola en la doctrina ${ }^{4}$ la prominencia de un derecho inalienable al ser humano, tan importante como el derecho a la vida misma, y es el derecho a la sepultura (ius sepulchri). El derecho a la sepultura, o derecho del hombre sobre su cadáver, carece de un reconocimiento expreso en los textos constitucionales estudiados. Esta ausencia es suplida con la implementación de leyes sobre cadáveres, cementerios y sanitarias que enmarquen su aplicabilidad.

La significación de la inhumación ha tenido un reflejo evidente en el tratamiento jurídico otorgado a cementerios y sepulturas. El formal reconocimiento de la sepultura como derecho constituye un elemento indispensable para una efectiva y real declaración del derecho fundamental de libertad religiosa, una de cuyas manifestaciones es el derecho a recibir sepultura digna ${ }^{5}$.

se haga responsable de los restos mortales. Se trata de justificar la posibilidad, real en la práctica, de que los herederos tomen decisiones sobre el destino del cadáver (De las Heras, 1987: 32). Messineo sostiene que se considera cosa al cadáver, puesto que con la muerte se ha dejado de ser persona y el sujeto se transforma en objeto (Bertoldi De Fourcade, 1983: 177).

4 Se reconocen derechos al cadáver en razón de las costumbres sociales, al respecto se plantea: «Asimismo, estamos viviendo actualmente en nuestro país todo un trabajo de la medicina forense y sus equipos de antropología, para responder al reclamo por la identidad de los cadáveres. Este derecho es reclamado también cuando se exige que cada cadáver sea enterrado o guardado en una urna con su nombre. No se puede realizar un acto, como extracción de los órganos de un cadáver, desconociendo que este mantiene aún muerto los derechos como persona» (Pfeiffer, 2006: 21).

5 Al respecto, Miguel Rodríguez señala: «Se trata de un derecho intrínseco a la dignidad propia del ser humano, aunque paradójicamente no suele estar como tal expresamente reconocido en las declaraciones y tratados internaciones de derechos humanos. Quizá, porque aquello que es tan evidente, tan indiscutible, hay ocasiones que basta con presuponerlo, sin que sea preciso formalizarlo de manera específica en un texto legal» (2015: 10). Otros notables investigadores del tema dan por sentada la prominencia de este derecho a la sepultura digna sin reparar en su definición (Fernández de Velasco, 1935: 207-237). De todo ello se entiende que la sepultura en sí misma, como dere- 
Desde estos criterios básicos, el presente artículo se orienta hacia una sistematización de los presupuestos históricos, teóricos y comparados de la sepultura en el ámbito de los derechos, a partir de un estudio teórico que permita conceptualizarla acorde con los principios y límites que la fundamentan.

\section{DESARROLLO}

\section{IMPLICACIONES SOCIALES Y JURÍDICAS DE LA MUERTE. BASES PARA LA DISQUISICIÓN DEL DERECHO A LA SEPULTURA}

La muerte es un fenómeno inevitable. Después de ocurrida, solo quedarán restos mortales que serán la muestra física de haber vivido sobre la tierra. Es, por tanto, parte de la vida humana como el hecho de nacer. Este temido suceso ha sido objeto de varias interpretaciones, criterios y creencias religiosas. La sociedad experimenta las repercusiones de su acontecimiento en sus diferentes esferas.

Momento controversial resulta la hora de confirmar cuándo se produce la muerte. En algunos casos se ha atendido a la putrefacción, al cese de la respiración, a la paralización cardiorrespiratoria y, en la actualidad, a la cesación de las funciones del encéfalo. Debe tenerse presente que la muerte, más que un instante, es un proceso evolutivo en que los principales actos vitales se van extinguiendo. Determinar el momento exacto de su ocurrencia no resulta fácil, debido a las condiciones en que puede suscitarse ${ }^{6}$.

Una de sus consecuencias inmediatas es, sin duda el proceso de duelo. Esta fase resulta más compleja cuando los familiares no tienen la oportunidad de tomar contacto con el cuerpo del ser amado. Del mismo modo, cuando la familia no ha podido enterrarlo, suele resultar más difícil la aceptación de la muerte como una realidad. Como resultado, el duelo por la pérdida puede convertirse en patológico o crónico ${ }^{7}$.

cho, enmarca la necesaria dignidad en su realización, por lo que resulta redundante sumarle tal categoría, que comprende a todos los derechos del hombre.

6 De la intrínseca complejidad del tema deriva lo difícil de la elaboración bioética del problema de la definición y determinación de la muerte y, por tanto, la necesidad de fundamentar una concepción determinada con la mayor integralidad posible. Es evidente que su marco sobrepasa los límites de cualquier disciplina particular y requiere la aportación de la filosofía, la teología, la antropología y la bioética, junto con las ciencias biomédicas (García, 1999a: 126-138) (García, 1998: 348-366) (García, 1999b: 1048-1053).

7 Proceso que se produce después de la pérdida de un ser querido. Existen en psicología teorías que describen cada una de sus etapas: shock, rabia, desesperación, y la cuarta, 
En este contexto, la muerte en su calidad de irreversible, se convierte en motor de los comportamientos humanos develados ante ella. Aspectos populares masivos y elementos claves de la vida sociocultural: flores, crucifijos, llanto, comidas, licores e inciensos, se conjugan en un solo momento. El velorio resulta la etapa liminal, en donde el muerto es objeto de tanatopraxis ${ }^{8}$, para, de este modo, convertirse en el eje protagónico del rito mortuorio?.

En algunas sociedades las emociones son expresadas con mayor facilidad; culturas como la francesa, española, italiana e inglesa son ejemplos de ello. Otras se caracterizan por tener una tendencia marcada hacia el autocontrol de las emociones y hacia un tipo de sufrimiento en silencio. Las culturas también poseen formas particulares de efectuar enterramientos, rituales funerarios y brindar diferentes tratamientos al cadáver.

Otro factor determinante en la concepción de la muerte es la religión. Esta es una variable con innegable influencia en todas las creencias o conceptos asumidos por la sociedad. El cese de la vida del hombre en la tierra es uno de los temas más tratados en las diferentes religiones. Los significados sostenidos por la institución eclesiástica acerca de la muerte, marcan las pautas de vida de sus feligreses ${ }^{10}$. Las tradiciones religiosas, por lo general, evitan mitigar o anular la muerte con promesas de supervivencia. Las religiones no ahorran a los hombres enfrentarse con la muerte. Afrontarla en toda su irremediable verdad es el comienzo de la sabiduría ${ }^{11}$.

\section{LA CONCEPCIÓN TEÓRICA DE LOS DERECHOS HUMANOS Y SU CLASIFICACIÓN. EL MARCO PROPICIO DE INSERCIÓN AL DERECHO A LA SEPULTURA}

Mientras que el término «derecho» alude a alguna prerrogativa o posibilidad de obrar de acuerdo con la voluntad, concedida por un ordenamiento positivo; "humano» refiere cierta cualidad o propiedad perteneciente al hombre genérico. De ahí que la existencia del derecho inherente a las personas

de reorganización de la conducta (Worden, 1997; Fonegra de Jaramillo, 2001: 13-14; Bolwby, 1980; Yoffe, 1998: 23-42).

8 Por tanatopraxis se entiende al conjunto de procedimientos sanitarios y ambientales requeridos para el adecuado tratamiento estético y de conservación temporal de un cadáver o restos humanos (Lipcovich, 2002).

9 Finol y Montilla (2004: 3-12). En Arabia Saudí, la versión wahabita del Islam prohíbe construir mausoleos. En el caso de la etnia de toraja de Indonesia, los funerales duran cinco días. De su realización depende alcanzar la condición de difunto (Armanian, 2013).

10 Muriá (2000).

11 Veizaga (2005: 6-22). 
por su calidad humana, sea independiente a su reconocimiento por un orden jurídico establecido, por lo que tiene sentido moral ${ }^{12}$.

Comenta Luis García San Miguel que los derechos humanos son exigencias, ideales frente a los órdenes establecidos. No en el sentido de utópicas, sino en el de fundadas en la moral. Cuando son formulados, se pretende que el orden jurídico positivo se ajuste a su contenido. No obstante, la definición de los derechos humanos no puede solo circunscribirse a ideales que guían el quehacer jurídico de un Estado o de la comunidad internacional ${ }^{13}$.

Para Nikken ${ }^{14}$ estos son los atributos de toda persona e inherentes a su dignidad, que el Estado está en el deber de respetar, garantizar o satisfacer. Ellacuría $^{15}$ resalta el objetivo de los derechos humanos al plantear: «[...] su objetivo no es otro que la liberación del hombre de todas sus enajenaciones, tanto materiales como espirituales [...]». Antonio Pérez Luño ${ }^{16}$ ofrece una definición acabada al enmarcarlo en el conjunto de facultades que, en cada momento histórico, concretan las exigencias de la dignidad, la libertad y la igualdad humanas. Deben ser reconocidas los ordenamientos a nivel nacional e internacional.

Según Luigi Ferrajoli ${ }^{17}$, el contenido de los derechos humanos está compuesto por todas las prerrogativas que sirven de basamento al desarrollo de una existencia digna. La vida, la libertad y la subsistencia forman parte de esas necesidades sustanciales. En la actualidad, aparecen los derechos económicos, sociales y culturales, que garantizan la existencia de condiciones de vida. Dadas las crecientes necesidades esenciales del hombre, su contenido se amplía a los derechos relacionados con la solidaridad, la protección del medio ambiente y el derecho a acceder al patrimonio común de la humanidad ${ }^{18}$.

En la actualidad, el caudal de prerrogativas va en aumento, por lo que el contenido de los derechos humanos es tendente a enriquecerse. En detrimento, cada derecho encuentra el máximo de su alcance, cuando interactúa con el legítimo ejercicio de otro. De este modo, su finalidad se encamina a garantizar la existencia digna del hombre. A partir de esta base, impone al Estado su positivación y respeto por el individuo social, a través de la puesta en práctica de mecanismos que aseguren el pleno ejercicio de estos derechos ${ }^{19}$.

\footnotetext{
Martínez (1995: 152).

García (1991: 86).

Mahtar M’ Bow (1982: 151).

Fernández (1988: 63).

Pérez Luño (2003: 38).

Ferrajoli (2004: 83).

8 Manili (1999: 25).

19 Tambussi (2005: 21-60).
} 


\subsection{La clasificación de los derechos humanos}

Los derechos humanos, como producto histórico, han tenido un reconocimiento gradual. Con un desarrollo aparejado al del propio ser humano, alcanzan cada vez mayor diversidad y número. Al desglose de los derechos, ha dado en llamársele clasificación o tipología. En algunos casos esta distinción tiene como finalidad establecer cuáles derechos son más importantes. En otros, se trata solo de establecer cuáles derechos surgieron primero. La relevancia de esta distinción de derechos estriba en lograr la participación de los individuos en la defensa de sus derechos, así como saber y poder utilizarlos ${ }^{20}$.

La clasificación que se maneja generalmente es la pronunciada por Karel Vasak y que distingue los derechos humanos de primera generación en civiles y políticos, que sirven para proteger al individuo de los excesos del Estado. Los derechos humanos de segunda generación están relacionados con la igualdad y comenzaron a ser reconocidos por los gobiernos después de la Primera Guerra Mundial. En su naturaleza son sociales, económicos y culturales, y aseguran la igualdad ciudadana de condiciones y trato. La tercera generación de derechos, surgida en la doctrina de los años ochenta, se vincula con la solidaridad. Los unifica su incidencia en la vida de todos, a escala universal, por lo que precisan de una serie de esfuerzos y cooperaciones en un nivel planetario ${ }^{21}$.

A partir de su historicidad, los derechos surgen como un concepto político que engloba una serie de libertades frente al Estado, pasando por una concepción de derechos cívico-políticos que se ejercen en el seno del Estado, para arribar a los derechos económicos-sociales y culturales, como categoría de derechos humanos distinta a las anteriores, en la que el Estado actúa como promotor y garante del bienestar económico y social, correspondiente al Estado social de derecho ${ }^{22}$.

Otros autores, y con menor grado de aceptación, han desarrollado otras categorías de derechos. Entre ellas destacan las enunciadas por Maurice Duverger ${ }^{23}$,

20 Volio (1978: 64).

21 Vasak (1984: 23-33).

22 Fernández (1981: 95).

23 El autor se refiere a los derechos humanos como libertades públicas de los gobernados, y los clasifica en libertades-límites, aquellas que encierran a la actividad gubernamental, y las libertades-oposición, como aquellas que procuran medios de oposición al gobierno (Duverger, 1970: 63-71). 
Sánchez Agesta ${ }^{24}$ y Loewenstein ${ }^{25}$. Resulta significativa la desarrollada por Jean Marquiset, que fuere apoyada por Fernando Volio. Utilizando como base el derecho natural, refiere la existencia de derechos del hombre sobre su cuerpo, los que se reconocen a la persona humana en el ejercicio de su actividad fisiológica ${ }^{26}$. Desde esta óptica los clasifica en las siguientes categorías:

Derecho a la existencia: la intangibilidad del cuerpo humano, protección a la vida intrauterina, el recién nacido, los menores de 15 años, el derecho de corrección, legítima defensa, el suicidio, la eutanasia y el duelo.

Derecho a la integridad personal: la reparación de las lesiones corporales, la libertad de movimientos, el derecho a la no mutilación, la vocación del peligro, el gusto del riesgo, el aspecto físico y la cirugía estética, el tatuaje, la defensa de la propia imagen, la donación de leche materna, sangre y semen.

Derecho a la salud: el derecho a la alimentación, al descanso, al autocuidado, la protección a la salud pública, la vigilancia de la salud individual.

Derecho a la vida sexual: la unión libre, la orientación sexual y el casamiento.

Derechos de la justicia sobre el cuerpo humano: la mano de la justicia, los derechos de la policía, la identificación del malhechor, la búsqueda de alcohol en sangre, los derechos del juez de instrucción, los informes médico legales, las penas corporales y la justicia civil.

Derechos del médico sobre el cuerpo humano: la intervención del médico, el contrato médico y su responsabilidad.

Derechos del hombre sobre su cadáver: libertad de funerales, respeto al cadáver, embalsamiento, integridad del cadáver, donación de órganos vitales y los trasplantes anatómicos.

Sobre este último, Marquiset considera que todo hombre tiene derecho, aun después de su deceso, al respeto y a mantener la forma íntegra de su cuerpo. Lo que implica interpretar que la protección y tratamiento de los restos del hombre, también forma parte de la dignidad de los humanos. Pilares estos sobre los que se asienta además el contenido del derecho a la sepultura, y que abarca a su vez los elementos étnicos y culturales que hacen de la muerte y despedida del difunto, un elemento consustancial a la naturaleza humana.

24 Para este autor se clasifican en cuatro grupos: los derechos civiles, los derechos públicos, los derechos políticos y los derechos sociales (Sánchez, 1985: 32).

25 Refiere su clasificación en tres categorías básicas: derechos civiles, los derechos de autodeterminación económica y las libertades políticas fundamentales (Núñez, 2006: 103-108).

26 Volio (1978: 66). 


\subsection{La tutela a la dignidad humana y la normatividad del derecho sobre el cadáver}

La dignidad humana se constituye en valor básico que cimienta los derechos humanos. Resulta una garantía de tipo negativo, por la cual protege a las personas contra vejámenes y ofensas de todo tipo. También afirma el pleno desarrollo de cada ser humano, a través de los derechos. El hombre conserva su dignidad desde el nacimiento hasta su muerte. Es el Estado, el encargado de reconocer, garantizar y promover la dignidad y los derechos humanos. Para ello, se vale de diversos mecanismos adecuados, prácticos y disponibles para prevenir sus violaciones y reaccionar contra ellas, unido a la necesaria condicionalidad material para su pleno disfrute ${ }^{27}$.

Varios autores tratan los mecanismos estatales para garantizar la plena satisfacción de la dignidad, y con ella, los derechos humanos. Estudiados como sistema de garantías, para Eduardo A. Russo ${ }^{28}$, estos se constituyen en mecanismos normativos como la declaración de inconstitucionalidad, la acción de amparo, el habeas data y el habeas corpus, además de los mecanismos informales, en donde señala la denuncia pública de la injusticia, la no cooperación y la desobediencia civil.

De otro modo, Fix-Zamudio ${ }^{29}$ considera una clasificación de instrumentos procesales para la protección de los derechos humanos divididos en indirectos, que pudieran encausarse a través de los procedimientos ordinarios instrumentados de acuerdo a su materia (civil, penal, laboral, etcétera). Los complementarios, utilizados para sancionar la violación consumada a través del juicio político o de responsabilidad de altos funcionarios, y la responsabilidad económica del Estado cuando su actividad ha quebrantado a los derechos humanos. Por último, los medios procesales específicos que ofrecen una rápida protección general y directa con efectos reparadores, requiriendo la restitución al afectado de los daños infringidos, la que coincide con la expresada por Mauro Capelleti. De acuerdo a su pragmática formulación, se acoge el criterio de Cutié Mustelier ${ }^{30}$, quien ofrece una detallada clasificación de estos mecanismos.

$27 \mathrm{Al}$ abordarse el tema de los derechos humanos, estos se constituyen como una expresión genérica donde pueden englobarse todos los tipos de derechos tanto los civiles y políticos como los económicos sociales y culturales, e incluso los de la tercera generación (Cutié Mustelier, 1999: 29).

28 Russo (2001: 127-141).

29 Fix-Zamudio (1974: 169-274).

30 Vale señalar que lo más importante no es crear todo un abanico de medios garantistas, sino que, en la práctica, estos sean eficaces y funcionen como un sistema de garantías, 
En resumen, más allá de sus categorías en jurisdiccionales, ordinarios o específicos, las no jurisdiccionales y las normativas, establece las premisas de todo sistema de garantías. Este sistema deberá estar dotado, a su criterio, de los tres subsistemas referenciados, instrumentados adecuadamente. La dignidad de la persona emana entonces de su naturaleza moral, libre y racional. La persona es el valor jurídico supremo y su dignidad es independiente a su edad, sexo, ciudadanía, capacidad intelectual o estado de conciencia. El derecho a la vida digna le asiste al ser humano solo por gozar de tal condición. El respeto de esta cualidad es la base del Estado de derecho ${ }^{31}$.

La importancia de la dignidad humana es decisiva para el derecho y en más de una de sus ramas se encuentran razones que la justifican. El derecho internacional impulsó la reflexión a partir de los horrores totalitarios que desembocaron en la Segunda Guerra Mundial. El Holocausto provocado por nazis y fascistas, y las matanzas colectivas propiciadas por el estalinismo, hicieron que todos los pueblos de la tierra iniciaran una nueva etapa de convivencia pacífica. La preservación de la dignidad de la persona fue el fundamento utilizado para alcanzar este objetivo.

En muchos instrumentos internacionales aparece la dignidad como colofón $^{32}$, de acuerdo a su calidad imprescindible, inalienable e irrenunciable del sujeto, erigida en la base y fundamento de los derechos humanos. De este modo, se interpreta que todo lo considerado como indispensable para la realización de una vida digna constituye, por naturaleza, contenido de los derechos humanos.

De lo anterior se entiende que la vigencia y aplicabilidad de los derechos humanos no se agotan con la vida del sujeto. Estos pueden extenderse hasta después de la muerte, con el objetivo de garantizar tratamiento y lugar de reposo al cadáver. Todo hombre merece que sus restos sean bien tratados, vivir confiado en que después de su deceso su cuerpo descansará en paz en las instituciones creadas al efecto.

de manera que en la concurrencia de todas las vías se logre la protección de los derechos humanos (Cutié Mustelier, 1999: 36-45).

31 Maihofer (2008: 45).

32 Desde la Declaración Universal de 1948, se recoge en el preámbulo y en el artículo primero su vinculación con la libertad y la igualdad. Asimismo, en el Pacto de Derechos Civiles y Políticos, de 16 de diciembre de 1966, se señala en su preámbulo que los derechos derivan de la dignidad inherente a la persona humana. Asimismo, una referencia aparece en el preámbulo del Pacto de Derechos Económicos, Sociales y Culturales de la misma fecha y en la Declaración y Programa de Acción de Viena, aprobados por la Conferencia Mundial de los Derechos Humanos el 25 de junio de 1993. Por su parte, la Declaración Universal de Derechos Humanos en su preámbulo, determina que todos los seres humanos nacen libres o iguales en dignidad y derechos (contenido previsto en la Convención Universal de Derechos Humanos). 


\subsection{Naturaleza jurídica de los derechos humanos}

Sobre la naturaleza de los derechos humanos existen dos perspectivas principales. La primera sostiene que los derechos humanos son aquellos que el Estado otorga en su orden jurídico. En esta perspectiva se encuentran diversas concepciones o matices positivistas. La segunda manifiesta que el Estado solo los reconoce y los garantiza en alguna medida. Desde esta visión se pondera al derecho natural y las diversas escuelas que lo tratan ${ }^{33}$.

La definición de la naturaleza jurídica de los derechos humanos permite trazar los fundamentos, objetivos y principios definitorios. Todo ello conlleva que su reglamentación y la exigencia de su respeto posean bases sobre las cuales erigirse. De este modo, la esencia de los derechos humanos se enmarca en las características propias que los distinguen ${ }^{34}$.

Entre ellos destaca la universalidad en sus postulados, que convierten a todos los hombres en titulares de derechos humanos, con independencia de su raza, color, sexo, orientación sexual, religión, ideología, nacionalidad o condición social. Prerrogativas estas que en modo alguno pueden ser anuladas, arrebatadas o negociadas a las personas, de ahí su carácter inalienable.

Asimismo, se consideran atribuidos al ser humano por el solo hecho de serlo, formando parte de su esencia, por lo que son inherentes al sujeto. Dando lugar la imposibilidad de desconocer la condición de un derecho como inherente a la persona, a su condición de irreversibilidad. Alejados de constituirse en una unidad cerrada y perfecta, los derechos humanos resultan perfectibles en su regulación y fundamentación. Experimentan una constante evolución, un desarrollo progresivo.

Los derechos humanos, junto con los valores y los principios, forman parte del contenido de justicia de una sociedad democrática moderna. Tienen como objetivo último ayudar a que todas las personas puedan alcanzar el nivel de humanización máximo posible, en cada momento histórico. Son medios para que la organización social y política permita el desarrollo máximo de las dimensiones que configuran la dignidad humana.

\section{CONCEPTO DE DERECHO A LA SEPULTURA, A PARTIR DE LAS CATEGORÍAS QUE LO INTEGRAN. SU NATURALEZA JURÍDICA}

Roma, el más grande de los imperios de la antigüedad, alcanzó un gran desarrollo en la mayoría de las ciencias. Las ciencias jurídicas sentaron bases

33 Las concepciones del derecho natural, a las que se acoge la presente investigación, afirman que la base de los derechos humanos se asienta en la dignidad humana (Maritain, 1942: 14-15; Nogueira, 2003: 10-12).

34 Mahtar M’ Bow (1982); Nava (2012). 
teóricas cuyos conceptos, valoraciones e instituciones se mantienen vigentes en la contemporaneidad. El derecho romano se convirtió en la base sobre la cual se implementó el sistema de derecho romano francés, acogido por un número considerable de Estados. Para los romanos, la muerte era un fenómeno decisivo para la vida en la eternidad, por lo que debían prepararse para ella mientras aún vivían. Es en esta época donde se escucha por primera vez del derecho sepulcral, constituido por tres factores fundamentales ${ }^{35}$.

\section{El ius mortuum inferre}

El primero de ellos se refiere al derecho sepulcral, cuya significación responde al derecho de ser sepultado. Este derecho se evidencia en tres modos diversos. El primero, en razón de ser heredero suis, a partir de la norma religiosa, elimina toda posible cesión voluntaria. El segundo, de acuerdo a un llamamiento testamentario, regido por normas civiles, abre la posibilidad de cesión, según el alcance y contenido del derecho heredado. El tercero nace de un llamado fundacional, y, a partir de la libre disposición, genera una acción personal y volitiva sucesoria, salvo expresión contraria. Aunque diferentes en sus orígenes, sus contenidos resultan idénticos, pues ninguno de ellos es enajenable.

\section{El ius sepulcri}

Basa su contenido neto en lo espiritual y religioso. El ius sepulcri soporta el embalsamamiento del cadáver y preparación para la «otra vida». Abarca los ritos funerales, el culto y todo lo que sea su consecuencia. Se extiende a su vez al derecho de tutela, cuidado y atención del sepulcro, mediante deberes piadosos y ceremoniales periódicos. No obstante, tienen un contenido real: impedir el enterramiento de quien no tuviera derecho al sepulcro cuya custodia le correspondía. Implicaba, además, la imposición de servidumbres al pasar por otras tumbas.

\section{El sepulchrum}

Este factor describe el lugar mismo de la sepultura. Constituye el espacio donde se deposita el cadáver íntegro (inhumación), o uno de sus miembros (cremación). Integrado por el aditus o acceso, y el espacio en torno o ambitus, con frecuencia cerrado, alcanza la totalidad del monumento. El resto del

35 La concepción de los factores integrantes del derecho a la sepultura o derecho sepulcral romano abordados en este epígrafe, son aportados por el jurista español Recaredo Fernández de Velasco, quien esboza este criterio a fin de esclarecer un tanto el enramado de la declaraciones legales que lo componían (Fernández de Velasco, 1935: 34-39). 
terreno en que se emplaza la sepultura sufre las consecuencias del aplazamiento, sin perder su condición jurídica.

El sepulcro trasciende como res religiosa o res divini iuris. Sometida bajo la disciplina del $f a$, se sustrae del comercio, deviniendo en res extra comercium. De este modo se excluye del patrimonio real, para integrarse a un patrimonio espiritual o religioso. Se enlaza así la muerte y la religión; la sepultura se penetra en el culto, una vez que el culto mismo se ha exteriorizado en la sepultura.

No bastaba el hecho material del enterramiento para que se constituyera la sepultura. Se requería, además, una inhumación real hecha a perpetuidad (conforme a derecho), en terreno dedicado a la sepultura. Nueve días después de la inhumación se vertía por tres veces la tierra sobre el sepulcro y este quedaba consagrado. La tumba, fuera de la esfera jurídico privada, se desliga de todo valor patrimonial y es objeto de una relación pública inmaterial. Era el Estado el encargado de prestar tales servicios al individuo romano.

Todos estos actos constituyen facultades personales e intransferibles. No obstante, tienen como contenido real impedir el enterramiento de quien careciera de derecho al sepulcro. Al respecto, el imperio romano atravesó un período oscuro, donde se aplicó una práctica desnaturalizada e inhumana. En los casos en que el causante era deudor de una relación jurídica, sus acreedores temerosos de no cobrar sus créditos se apoderaban del cadáver del deudor reteniéndolo mientras la familia no reconocía la deuda. En caso de incumplimiento del pago por los herederos, los acreedores mutilaban y despedazaban el cadáver.

De estos tres elementos constitutivos del derecho a la sepultura, y a partir de las consideraciones que enmarcan su contenido, no queda sino plantear una definición teórica de tal derecho. Pues si bien algunos autores refieren la existencia del derecho a la sepultura digna, y otros enmarcan con certeza las categorías que lo integran ${ }^{36}$, lo cierto es que hasta hoy la doctrina no ha ofrecido una conceptualización que lo contenga.

Por lo que, de acuerdo a los criterios ya asentados, el derecho a la sepultura deviene en el conjunto de facultades protectoras a la libertad de funerales y al respeto, embalsamamiento e integridad del cadáver, de acuerdo a los valores étnicos y culturales propios que no contradigan la moral generalmente aceptada, destinadas a garantizar el lugar de reposo definitivo, cuya plena realización solo es posible con el reconocimiento legal de sus contenidos y la creación de mecanismos estatales para su protección.

\subsection{Naturaleza jurídica del derecho a la sepultura}

Sin lugar a dudas, la sepultura, más allá de la concepción física del lugar en donde se depositan los restos humanos, se erige en un derecho que

36 Fernández de Velasco (1935: 207-237); Rodríguez (2015: 10); Volio (1978: 66). 
traspasa los umbrales de la muerte. Ello nos permite afirmar que toda persona independientemente a su condición social o física, tiene derecho a decidir el tratamiento que prefiere para sus restos mortales, siempre que no contravenga los órdenes de la moral y la salubridad, por lo que deviene en un derecho intrínseco a la dignidad propia del ser humano ${ }^{37}$.

Sin embargo, su reconocimiento no aparece en las declaraciones y tratados internaciones de derechos humanos. Tal vez se deba a que, al resultar tan evidente, basta con presuponerlo, sin que sea preciso formalizarlo de manera específica en un texto legal. Alguna referencia al respecto se advierte en los cuatro Convenios de Ginebra de 12 de agosto de 1949 sobre Derecho Internacional Humanitario. Particularmente, el art. 130 del IV Convenio reconoce el derecho de las personas fallecidas a recibir sepultura, al regular que las personas fallecidas en cautiverio sean enterradas dignamente, si es posible con arreglo a los ritos de la religión a que pertenezcan, y de que sus sepulturas sean respetadas, convenientemente conservadas y marcadas de modo que se las pueda localizar en cualquier momento.

El derecho a la sepultura, además de formar parte de la dignidad inalienable de toda persona, tiene además un nexo indisoluble con el derecho de libertad religiosa. Tanto así que la significación religiosa de la muerte y la inhumación hace del enterramiento un acto estrechamente vinculado a las creencias y sentimientos religiosos. No puede hablarse de libertad religiosa, si aparejadamente, no se respetan las prácticas funerarias, de acuerdo con las creencias del occiso o sus familiares sobrevivientes.

En correspondencia, a la sepultura como derecho humano, resultan aplicables a este los rasgos distintivos de la naturaleza de los derechos humanos, que permiten enmarcarlo en esta categoría. Actúa entonces como elemento esclarecedor y determinante, a la hora de afirmar que el derecho a la sepultura, por su naturaleza y contenido, forma parte de los reconocidos derechos humanos de segunda generación.

Todo ello permite afirmar su universalidad y aplicabilidad a toda la humanidad sin distinción de raza, sexo, creencia o nacionalidad. Este derecho tiene en su contenido la libertad de funerales, permitiendo al hombre desarrollar actos solemnes, propios de su cultura en cualquier lugar que se encuentre, aun en condición de emigrante. Su prerrogativa inalienable impide que pueda ser invalidada a ningún hombre. Dado a este carácter, es necesario que el Estado garantice la existencia de instituciones que materialicen el derecho y la creación de leyes contenedoras de presupuestos que lo garanticen. Solo así será posible su ejercicio y contrarrestar las transgresiones en su práctica.

Como derecho inherente al ser humano, resulta una expresión de la esencia espiritual y consciente del hombre. Con el objetivo de darle trata-

37 Rodríguez (2015: 12). 
miento y reconocimiento a un fenómeno impregnado a la vida humana, cuyo acontecimiento es inevitable, surge el derecho a la sepultura. De igual forma, los servicios funerarios devienen en prestaciones brindadas por el Estado o un particular, que satisfacen necesidades básicas. Destaca además su carácter irreversible, por su inherencia a la persona misma, desde el momento del nacimiento. Impregnado a las tradiciones de la humanidad, cobra inestimable valor por su relación con el honor del causante, y en consecuencia, por cuestiones ineludibles de salubridad y prevención de enfermedades ${ }^{38}$.

Como resultado, las tendencias internacionales en materia de derechos humanos se inclinan a la posible configuración de nuevos derechos y a la redefinición de los contenidos de los ya existentes. Siendo así, es posible extender el ámbito de la protección a derechos anteriormente desestimados. Las sucesivas generaciones de derechos humanos y la multiplicidad de los medios para su protección son ejemplos fehacientes de ello.

Dentro del contenido de los derechos humanos de segunda generación, se aborda el derecho a un nivel de vida adecuado que asegure al hombre y a su familia los servicios sociales necesarios. Los servicios funerarios, a partir de su íntima relación con el derecho a la sepultura, resultan imprescindibles para satisfacer necesidades básicas de la población. Se puede afirmar que los derechos involucrados a estos servicios y las instituciones que los brindan tendrán siempre vigencia y aplicabilidad.

\section{LÍMITES Y CONTENIDO DEL DERECHO A LA SEPULTURA. BASES PARA SU CONSTRUCCIÓN TEÓRICA}

Como se ha visto, la sepultura encontró en las costumbres de los pueblos sus primeros cimientos. Ha sido el derecho administrativo quien estableció las pautas regulatorias en torno a las limitaciones en su ejercicio, al imponer, en razón de la salubridad pública (en el caso de la inhumación), y el interés social (en las cuestiones referentes a las donaciones de órganos de cadáveres), sus pautas generales.

La consecuente instrumentación de sus límites ha quedado a la deriva, al insertarse dentro de otros derechos. Cuestiones como el derecho a disponer en testamentos de determinadas prácticas mortuorias, en razón de voluntades propias o religiosas que atenten contra la colectividad o el derecho subjetivo ajeno, no alcanzan una regulación normativa que logre enmarcarlos. La discordia entre parientes sobre la ubicación definitiva del difunto, ritos fúnebres y donación de órganos quedan en terreno de nadie. Tampoco se logra definir dentro de qué campo del derecho deberá desarrollarse, al involucrar

38 Fenoglio (2012: 17-26). 
cuestiones de diversas naturalezas que impiden su contextualización en uno u otro.

Ha sido la actividad jurisdiccional la que se ha visto precisada a determinar los preceptos teóricos en los que pudiera enmarcarse a la sepultura como derecho. Ante legislaciones que no proporcionan respuestas claras sobre esta materia, se advierte la presencia de una auténtica laguna legal, que deberá ser salvada acudiendo a medios de integración como la analogía, la aplicación de principios generales del derecho, como el de buena fe, y el recurso a la costumbre o a los usos sociales como fuente normativa supletoria.

Ante estas prerrogativas, los jueces han de ajustar todas las piezas dentro del sistema para que este sea un todo armónico. Para ello han de incorporar, en su caso, las categorías que sean necesarias para determinar la prevalencia entre cada uno de los derechos confrontados y sus consecuentes amparos en una $\mathrm{u}$ otra norma; además de los problemas que suscita la aplicación de las técnicas de protección de los derechos fundamentales y libertades públicas, y otros muchos que podrían citarse ${ }^{39}$.

Tomando como punto obligado de referencia a la Constitución, que es en definitiva la base sustentadora que da unidad al sistema ${ }^{40}$, cabe referir, en este sentido, pronunciamientos de tribunales nacionales que asientan bases en la construcción teórica que se persigue. La Sentencia T-741/14 de 8 de octubre de 2014, de la Corte Constitucional de Colombia ${ }^{41}$, asienta criterios en cuanto al culto, en las distintas religiones del mundo, como un elemento inescindible de la creencia, razón por la cual en la Constitución se protege su libre manifestación.

Por ello, esta Corte fijó algunas reglas jurisprudenciales en torno a su salvaguarda, al reconocer que los familiares cercanos son los únicos que tienen el derecho a la disposición del cadáver de un ser querido. Esa disposición se debe ejercer con respeto por el cuerpo inerte y, en ningún caso, tal titularidad se asemeja a la propiedad o la posesión. Además, todo acto que impida injustificadamente el ejercicio de un culto religioso vulnera los derechos fundamentales a la libertad de cultos y de conciencia. La incapacidad económica de los familiares para asumir los costos del traslado, exhumación y/o inhumación de cadáveres no puede ser un obstáculo para el ejercicio de los ritos fúnebres ${ }^{42}$.

39 Las cuestiones litigiosas que puede suscitar el destino de los restos humanos surgen, normalmente, en el marco de un conflicto familiar previo, siendo situaciones de gran coste personal para los implicados y de difícil arreglo pacífico (Mariño, 2015).

40 Bocanegra (1982: 12).

41 Sentencia T-0741-14 - Derechos a la libertad de cultos y a la libertad de conciencia. Traslado, exhumación e inhumación de cadáveres.

42 Tales rubros deben ser cubiertos por los entes municipales, en virtud del Decreto 1333 de 1986 de la República de Colombia, por el cual se expide el Código de Régimen Municipal. 
En conclusión, para esta Corte ${ }^{43}$ es claro que permitir la manifestación de las ceremonias o ritos de muerte, a través del derecho de los familiares a trasladar, exhumar o inhumar el cadáver de un ser querido, resulta parte esencial del respeto y protección del derecho a la libertad de culto. El sustento teórico de esta sentencia, en ausencia de normas específicas, se basa en la jurisprudencia establecida por sentencias anteriores.

Entre ellas cabe destacar la sentencia T-162 de $1994^{44}$, en la que la propia Corte precisó que tienen prioridad en la disposición del cadáver el o la cónyuge o compañero(a) permanente, los hijos, los padres, los hermanos, los abuelos o los nietos del fallecido. Sin embargo, aclaró que esa potestad que tienen los familiares debe estar regida por el respeto al cuerpo inerte $y$, en ningún caso, tal titularidad se asemeja a la propiedad o la posesión. Así mismo, estableció que solo frente a estas personas se configura el derecho a la libertad de cultos y de conciencia en relación con la sepultura del cuerpo.

En ese fallo se efectúo una reflexión sobre el valor simbólico del cadáver y la significación del entierro católico. Frente a esto se explicó que al vincularse la muerte con profundas elaboraciones simbólicas y religiosas, el culto o rito mortuorio adquiere total trascendencia para que las personas puedan efectuar con mayor facilidad el duelo y reelaborar sus relaciones psíquicas con el difunto. De otro modo, la Sentencia T-462 de $1998^{45}$ precisó que la pretensión de una persona de venerar la tumba de un ser querido se encuentra protegida en la Constitución por el art. 19 Superior ${ }^{46}$. De manera que el sepulcro, concebido

43 El numeral $4^{\circ}$ del art. 60 del Decreto 2591 de 1991 precisa que la acción de tutela resulta improcedente cuando sea evidente que la violación del derecho originó un daño consumado, salvo cuando continúe la acción u omisión violatoria del derecho. Esta Corte estableció que la razón de ser de dicho numeral es la efectividad del amparo constitucional (comentarios de la Sentencia T-0741/14 de 8 de octubre de 2014).

En esta sentencia se revisó un caso en el que una familia que había enterrado a su padre se vio sorprendida por la decisión de un hijo extramatrimonial de trasladar los restos del difunto a otro cementerio. Ante esos hechos, la Corte resolvió dos interrogantes «el primero, ¿quién tiene derecho a exhumar un cadáver?, y, el segundo, ¿quién tiene derecho a inhumarlo?» (comentarios de la Sentencia T-741/14 de 8 de octubre de 2014).

45 En esta sentencia se conoció de una señora que solicitaba el traslado del cadáver de su esposo a un cementerio católico, pues este había sido enterrado como $\mathrm{NN}$, después de haber desaparecido. Las autoridades de salud pública impedían la exhumación y el traslado correspondiente porque el difunto no llevaba más de 4 años inhumado, tal y como lo exigía la norma sanitaria (comentarios de la Sentencia T-741/14 de 8 de octubre de 2014).

46 La Constitución Política de Colombia de 1991, reformada en 1997, expone en su art. 19 Superior que se garantiza la libertad de cultos. Toda persona tiene derecho a profe- 
como una práctica simbólica de valores religiosos, adquiere una connotación jurídica.

Por tanto, después de reiterar su jurisprudencia, esta corporación declaró vulnerado el derecho fundamental al culto, ya que se le había impedido a la actora realizar la ceremonia de muerte de su compañero y otorgarle un lugar digno donde pudiera rendirle honor y efectuar su duelo. Por último, hace referencia a la Sentencia T-165 de $2013^{47}$ el derecho a la libertad de cultos, en este aspecto específico relacionado con la sepultura de cadáveres, conforme a los ritos de los familiares o del difunto, para gemelos nonatos.

Otro tanto aporta la Corte Interamericana de Derechos Humanos, que desarrolla un papel relevante en la lucha por los derechos humanos. A su arbitrio se someten posibles violaciones, ocurridas en los Estados americanos sometidos a su jurisdicción. En los casos referentes al derecho a la vida, siempre han sido analizados en relación con violaciones de otros derechos. Esto se debe a la concepción asumida por la Corte de que la vida es la base ontológica de todos los otros derechos y que su violación es irreversible porque implica la desaparición de su titular ${ }^{48}$.

sar libremente su religión y a difundirla en forma individual o colectiva (Constitución Política de Colombia, actualizada con los Actos Legislativos a 2015. Edición Especial preparada por la Corte Constitucional).

47 Una mujer reclamaba el traslado a su municipio de origen de dos fetos sin vida que le extrajeron de su vientre en un hospital de Bucaramanga. Para ella se hacía indispensable realizar el entierro conforme a los ritos cristianos. Para esta Corte, tal petición fue un ejercicio válido de la libertad de cultos y de conciencia, por lo que ordenó el traslado de los cuerpos de los no nacidos a su lugar de origen (comentarios de la propia Sentencia T-741/14, de 8 de octubre de 2014, de la Corte Constitucional de Colombia).

48 El primer caso con estas características fue el de Bámaca Velásquez, de 25 de noviembre de 2000. Según la denuncia, Efraín Bámaca Velásquez desapareció el 12 de marzo de 1992, después de un enfrentamiento entre el ejército y la guerrilla que se produjo en la aldea de Montúfar, en la región oeste de Guatemala. Las fuerzas armadas encarcelaron al señor Bámaca Velásquez secretamente en varias dependencias militares donde le torturaron y le ejecutaron (caso Bámaca Velásquez: Serie C No. 70. Sentencia de 25 de noviembre de 2000. La condena del Estado por la falta de respeto a los restos mortales de las víctimas. Voto Concurrente del juez A. A. Cançado Trindade. Sentencia de 14 de marzo de 2001). Este fue el primer caso sobre desaparición forzada de personas en el cual fue considerada la cuestión de la falta de respeto a los restos mortales de la víctima y el sufrimiento que esto causa a sus familiares. En el caso de Neira Alegría de 1995 no se logró identificar los restos mortales de las víctimas, y sentenciaron "la negligencia y la falta de respeto con los restos mortales de las víctimas». 
A partir del año 2000, la Corte Interamericana introduce la importancia del respeto a los restos mortales en sus sentencias. Considerando la protección de los restos mortales como una extensión del derecho a la vida, se plantea la necesidad del hombre no solo a vivir una vida digna, sino también mantener la dignidad hasta después de la muerte. En las anteriores resoluciones, los jueces integrantes de la Corte reflejan sus consideraciones con respecto a la protección de los restos mortales ${ }^{49}$. De forma creadora incluyen el tratamiento formal y respetuoso al cadáver como parte o contenido de los derechos humanos. Tanto la vida como la muerte deben ser vistas y realizadas de forma digna.

\subsection{El derecho sobre el cadáver en el contexto normativo internacional}

En la actualidad los ordenamientos jurídicos configuran un número cada vez más creciente de derechos, con el objetivo de proteger y salvaguardar las prerrogativas atribuidas al hombre. Las sociedades, con el paso del tiempo, han experimentado transformaciones importantes como el surgimiento de nuevas instituciones, la redefinición de antiguos conceptos, los nuevos derechos erigidos sobre la base de la necesidad humana de justicia, entre otras.

La historia de la humanidad, en cada una de sus etapas, ha tenido sus características propias, en correspondencia con las condiciones materiales del período. De la misma forma, las exigencias del mundo contemporáneo van en aumento, sobre todo las de perspectivas legales. En cuanto a la regulación de los derechos sobre el cadáver, varios son los países que han normalizado actos relacionados con el deceso. En una selección previa, se ha decidido utilizar como referentes, en el contexto latinoamericano, la legislación de México y Chile, a partir de sus arraigadas concepciones en el tratamiento de este derecho en América Latina, que ilustran las perspectivas normativas asentadas.

En tanto, se selecciona a Puerto Rico al encabezar la vanguardia en las regulaciones de última generación en torno al derecho a la sepultura, proyectando el alcance y dimensionamiento de este derecho bajo el resguardo de la Administración pública. El análisis se enfoca a partir de tres parámetros fundamentales: en cuanto a la libertad de actos fúnebres y velatorios, la obligación estatal en la prestación de los servicios de inhumación y enterramiento y, por último en cuanto al carácter público de su realización.

La regulación chilena carece de una normación específica para el tratamiento de cadáveres, cuyas cuestiones son poco abordadas en la Ley 357 «Reglamento General de Cementerios» de 15 de mayo de 1970 en concordancia

(caso Neira Alegría y Otros: Serie C No. 20. Sentencia de 19 de enero de 1995. La condena del Estado por la desproporción en el uso de la fuerza policial).

49 Cenedeci (2005: 74-112). 
con lo informado por el Servicio Nacional de Salud mediante oficio 8.531, de 8 de mayo de 1970, y lo dispuesto en el Libro VIII del Código Sanitario del propio país. Esta reconoce en su art. 27 la obligación de los cementerios públicos en la prestación de servicios de sepultaciones, exhumaciones, incineraciones, capillas o velatorios, entre otros, que estarán a cargo del personal del cementerio.

Relevante resulta lo estipulado en el art. 46, acápite 12, en el que instituye, dentro del recinto cementerial, la existencia del archivo de documentos otorgados ante notario sobre manifestaciones de última voluntad, acerca de disposiciones de cadáveres y restos humanos. Vale significar la prevalencia de la intervención administrativa del art. 49, por razones de salubridad pública, en la obligación de prestar servicios de inhumación y enterramiento por los cementerios públicos, salvo que exista una justa causa calificada por la autoridad sanitaria.

Otra cuestión notable que asienta la formulación de este derecho es que según la Ley 19.451, de 3 de marzo de 1986, sobre trasplante y donación de órganos, toda persona mayor de 18 años es considerada donante de sus órganos una vez fallecida. Se exceptúa cuando haya manifestado en vida su negativa a ser donante, en alguna de las formas que establece la ley. El médico que dude sobre la voluntad de un fallecido de ser donante deberá consultar al cónyuge o a su conviviente. Si este no está presente al momento de tomar la decisión, deberá consultarse a los parientes u otras personas en el orden que establece la ley.

En caso de que los testimonios sean contradictorios o no sea posible ubicarlos en un plazo razonable, la persona será considerada donante. Este tratamiento evidencia la significación social que alcanza el cadáver como res publica, lo que lo deja al dominio del Estado con respecto a sus órganos. De acuerdo a este criterio cada chileno resulta un donante en potencia, a menos que exista declaración clara y precisa en contrario.

Por último, y de acuerdo al carácter público en la prestación de estos servicios, en el art. 53 de la referida Ley 357 expresa la obligación de dar sepultura a un cadáver al cónyuge sobreviviente o pariente más próximo que esté en condiciones de sufragar los gastos. Para el caso de los indigentes, serán sepultados en el cementerio de la localidad en que haya ocurrido el deceso gratuitamente a petición de la autoridad. Se limita así la obligación administrativa hacia aquellas personas que, por razones de precariedad, no pueden asistirse estos servicios. Criterio que se sustenta en los referidos presupuestos de salubridad y sanidad pública.

Con respecto a la legislación mexicana, un paso significativo en la libertad de actos fúnebres y velatorios fue la Ley de secularización de los cementerios de 1859. Con ella se transmiten al dominio público los lugares de enterramientos, y con ellos, los servicios y tratamiento a cadáveres. El Reglamento de Cementerios del Distrito Federal de los Estados Unidos Mexicanos de 20 de diciembre de 1984 reconoce el establecimiento, funcionamiento, 
conservación y operación de cementerios en el Distrito Federal, como servicio público que comprende la inhumación, exhumación, reinhumación y cremación de cadáveres, restos humanos y restos humanos áridos o cremados.

Con mayor acierto que la legislación chilena, establece reglas generales para el tratamiento de cadáveres a través del Reglamento de la Ley General de Salud en materia de control sanitario de la disposición de órganos, tejidos y cadáveres de seres humanos, del 20 de febrero de 1985. Esta norma provee en la esfera administrativa, el cumplimiento de la Ley General de Salud, en lo que se refiere al tratamiento de cadáveres con fines terapéuticos, de investigación y de docencia. Es de aplicación en toda la República y sus disposiciones son de orden público e interés social.

En contraposición a lo establecido en la legislación chilena, en ningún caso se podrá disponer de órganos, tejidos y sus derivados, productos y cadáveres, en contra de la voluntad del disponente originario. En este aspecto se entiende que solo podrá trasplantarse aquellas personas fallecidas que con antelación hubiesen informado su consentimiento. En caso contrario, se atenderá al criterio de sus familiares allegados de acuerdo a un orden prelatorio, sin cuya autorización no podrá efectuarse tal práctica sobre el resto humano.

La obligación estatal en la prestación de los servicios de inhumación y enterramiento dispone en el mencionado Reglamento de Cementerios que tales prestaciones estarán sujetas a las tarifas aprobadas. En correlación a la legislación chilena, el servicio funerario gratuito será proporcionado a las personas indigentes por el Departamento del Distrito Federal por conducto de la Dirección General Jurídica y de Estudios Legislativos o de las oficinas de Panteones Delegacionales. Este servicio comprende la entrega del ataúd, el traslado del cadáver en vehículo apropiado, fosa gratuita bajo el régimen de temporalidad mínima y exención de los derechos que con motivo del servicio hubieren de cubrirse a la Tesorería del Distrito Federal.

Notorio resulta el tratamiento que a la configuración de un legítimo derecho a la sepultura estipula el ordenamiento jurídico de Puerto Rico. De las legislaciones foráneas estudiadas, esta muestra un paso de significativo avance, al lograr reunir en un mismo cuerpo normativo todas las cuestiones relativas al tratamiento del cadáver, velatorios y la obligación estatal en la prestación de los servicios de inhumación y enterramiento. Mediante la Ley 258 de 15 de septiembre de 2012, "Ley de Servicios Funerarios de Puerto Rico", ofrece un tratamiento normativo para el cadáver desde la propia muerte, el traslado de cadáveres, las honras funerarias, el embalsamamiento y el velatorio hasta la inhumación y exhumación de cadáveres.

Inicia su articulado con un reconocimiento expreso, como política pública del Pueblo de Puerto Rico, al reconocer que la dignidad del ser humano es inviolable, y que ese fundamental principio trasciende la vida natural y se proyecta hacia la posteridad. Por lo que el trato dado a toda persona fallecida, y en consideración a sus deudos, debe estar revestido del 
mayor grado de dignidad, consideración y respeto, en un plano de justicia esencial sostenido por los valores de la cultura occidental de la cual se considera parte. Este pronunciamiento marca la vanguardia en la plena significación de un derecho pleno a la sepultura.

Del estudio de su contenido se advierte que, para resultar una ley tan abarcadora, ha dejado fuera de su ámbito de aplicabilidad cuestiones imprescindibles en su tratamiento. Tal es el caso de la libertad de funerales, cuestión sobre la que no esboza pronunciamientos específicos. En este sentido, destaca su regulación en torno a los requerimientos de embalsamamiento, al apuntar que, cuando por motivos de creencias religiosas no se realice el embalsamamiento del cadáver, se podrá realizar el traslado, siempre que se haga en un ataúd sellado de metal.

En estos casos se deberá obtener un permiso especial emitido por el Departamento de Salud. Así mismo, plantea que la exposición del fallecido, para los efectos de esta ley, no estará sujeta a formas y maneras específicas o particulares, y no tendrán limitaciones, salvo cuando se afecte la salud, la moral o el orden público. De este modo muestra una frugal protección a la determinación propia de difuntos y familiares al respecto, al circunscribirse a establecer los límites en la realización de este derecho.

Otro aspecto significativo resulta su falta de referente al respeto a la integridad física del cadáver y evita abordar cuestiones relativas a los trasplantes de órganos. Aunque estipulado como servicio público, especifica que toda empresa o establecimiento dedicado a la prestación de bienes y servicios funerarios proveerá a todo cliente una lista o relación de los costos o precios de cada uno de los bienes y servicios que ofrece. De este modo, desprotege a las personas en estado de indigencia que quedan fuera del abrigo de esta ley.

Como en la totalidad de las normas estudiadas, no se pronuncia en cuanto a la solución de los conflictos que en el ejercicio del derecho a la sepultura pudieran suscitarse. Partiendo de su estricto marco administrativo, esta ley, al igual que las regulaciones estudiadas, se aleja de la confrontación de intereses que pudiera generarse por disposiciones testamentarias o voluntad de parientes que trasciendan a lo regulado. De acuerdo a la práctica jurídica seguida por estos países, ha sido el marco civil el escogido para la solución de estos conflictos, campo que tampoco ofrece vías específicas para su tratamiento. De este modo, jueces y abogados se arman de principios generales del derecho y costumbres funerarias asentadas para dirimir estos conflictos. En estas cuestiones queda un campo abierto por aportar en materia de límites y garantías a este derecho.

El cadáver, cuerpo sin vida del ser humano, históricamente no ha sido protegido por documentos jurídicos. La costumbre, fuente no formal del derecho, suplió la ausencia de normatividad relacionada con el seguimiento y tratamiento que se le debía brindar a los restos mortales. Los textos legales estudiados con aspectos relacionados al tema, tratan la necesidad de los enterramientos por razones de salubridad en las ciudades, en el ámbito 
administrativo. Cuestiones estas que los sitúan en iguales desventajas que las normas cubanas promulgadas al respecto.

En las nuevas condiciones generadas en el mundo actual, no solo existe preocupación por la sanidad, sino por garantizar respeto e integridad al cadáver. Brindar todos los mecanismos y garantías necesarias es la responsabilidad del Estado, para alcanzar la dignidad plena del hombre, incluyendo el cuidado y ceremonia formal al cuerpo físico sin vida del hombre.

\section{CONCLUSIONES}

El derecho a la sepultura tiene sus cimientos en la concepción misma de la muerte, como hecho natural a escala social, cultural y religiosa. Desde la antigüedad, el tratamiento al cuerpo humano sin vida ha encerrado un conjunto de manifestaciones ideológicas que fundan las costumbres mortuorias mantenidas hoy en día. Su contenido incluye la libertad de funerales, respeto al cadáver, embalsamamiento, integridad del cadáver, donaciones de órganos y descanso definitivo a partir de sus tres elementos distintivos: el cadáver, la sepultura y el cementerio.

Así mismo, la regulación jurídica no ha seguido la evolución histórica y social del cadáver. Los textos legales promulgados con aspectos relacionados al tema tratan la necesidad de los enterramientos, tratamientos de cadáveres y servicios funerarios, por razones de salubridad pública, estableciéndose sus limitaciones fundamentales en el contexto administrativo. Nada norma los límites en el ejercicio de derechos análogos o coincidentes en la sepultura, siendo la práctica jurisdiccional quien ha establecido, a partir de los medios de integración, las dimensiones formales a este derecho. Para ello asientan criterios sobre la responsabilidad de los familiares sobre el cadáver y el deber de enterramiento, a través de un orden prelatorio. En esta misma medida reconocen la manifestación de las ceremonias o ritos de muerte como parte esencial del respeto y protección del derecho a la libertad de culto. Advierten, a su vez, que esa potestad de los familiares debe estar regida por el respeto al cuerpo inerte y, en ningún caso, tal titularidad se asemeja a la propiedad o la posesión.

De este modo, puede enfatizarse que, en la actualidad, la preocupación por la sanidad pública ha cedido interés en pos de potenciar un legítimo derecho entorno al cadáver, sepultura y cementerio, que garantice el tratamiento digno de los restos humanos. En esta cuestión, la figura del Estado protector se alza como elemento insigne.

\section{Bibliografía}

Agesta Sánchez, L. (1985). Lecciones de Derecho Politico. Madrid: Civitas. Albaladejo, M. (2002). Derecho Civil I. Barcelona: Bosch. 
Armanian, N. (2013). Morir y ritos mortuorios en Oriente Próximo. Público.es. Disponible en: https://blogs.publico.es/puntoyseguido/1110/1110/.

Barandarián, J. L. (2002). Tratado de Derecho Civil. Lima: Gaceta Jurídica.

Bertoldi de Fourcade, M. V. (1983). Trasplante con órganos de cadáveres. Buenos Aires: Hammurabi.

Bocanegra, R. (1982). El valor de las sentencias del tribunal constitucional, Madrid: Instituto de Estudios de Administración Local.

Bolwby, J. (1980). La pérdida afectiva: tristeza y depresión. Buenos Aires: Paidós.

Borda, G. A. (1994). Tratado de Derecho civil-sucesiones. Madrid: Abeledo-Perrot.

Cenedeci, R. (2005). El nuevo concepto del derecho a la vida en la jurisprudencia de la Corte Iberoamericana de derechos humanos. Revista del Foro Constitucional Iberoamericano, 9, 74-112.

Cutié Mutelier, D. (1999). El sistema de garantías de los derechos humanos en Cuba [tesis doctoral]. Universidad de Oriente, Cuba.

De las Heras, G. (1987). La consideración del cadáver en el Derecho Romano (su posible repercusión en la actualidad). Albacete: Bomarzo.

Díez-Díaz, J. (1983). Los derechos físicos de la personalidad. Madrid: Santillana.

Duverger, M. (1970). Instituciones Politicas y Derecho Constitucional. Madrid: Tecnos.

Fenoglio, N. C. (2012). Documentos de cementerios, identificación y valor. Sevilla: Universidad Internacional de Andalucía.

Fernández de Velasco, R. (1935). Naturaleza jurídica de cementerios y sepulturas: historia y problemas jurídicos. Revista de Derecho Privado.

Fernández, E. (1981). El problema de los fundamentos de los Derechos Humanos. Revista Anuario de Derechos Humanos, 1, 95.

Fernández, J. (1988). Seminario sobre derechos humanos. La Habana: Instituto Interamericano de Derechos Humanos.

Ferrajoli, L. (2001). Los fundamentos de los derechos fundamentales. Revista Primera Vista, 18, 26-42.

- (2004). Derechos y garantías: la ley del más débil. Madrid: Trotta.

Finol, J. E. y Montilla, A. M. (2004). Rito y Símbolo: Antropo-Semiótica del velorio en Maracaibo. Revista de Ciencias Humanas y Sociales, 45, 3-25.

Fix-Zamudio, H. (1974). Introducción al estudio procesal comparativo de la protección interna de los derechos humanos. En VV.AA., Veinte años de evolución de los Derechos Humanos (pp. 160-274). México, D.F. Instituto de Relaciones Jurídicas.

Fonegra de Jaramillo, I. (2001). De cara a la muerte. Cómo afrentar las penas, el dolor y la muerte para vivir plenamente. Santiago de Chile: Andrés Bello.

García, L. (1991). ¿Qué son los derechos humanos? Revista del Instituto Bartolomé de las Casas, 2, 84-98.

García, O. (1998). La unidad de la persona humana y su fundamentación neurológica: el sustento de una nueva racionalidad para la comprensión de la muerte y de otros problemas bioéticos. Cuadernos de Bioética, 34, 348-366.

- (1999). La definición y determinación de la muerte: una opinión diferente. Cuadernos de Bioética, 40, 38-63.

Lipcovich, P. (2002). Secretos de la tanatopraxia. Periódico Digital de Argentina. 
Mahtar M'Bow, A. (1982). Las Raices del Futuro. Paris: Imprimerie de la Manutention. Maihofer, W. (2008). Estado de Derecho y Dignidad Humana. Madrid: Editorial B de F. Manili, P. (1999). La difícil tarea de elaborar un concepto de los Derechos Humanos. Revista Jurídica de la UCES, 1, 23-46.

Mariño, F. (2015). El destino de los restos mortales. La Sentencia del Tribunal Supremo de 4 de noviembre de 2015 y otras resoluciones judiciales. Iuris Prudete [blog de derecho privado].

Maritain, J. (1942). Les Droits de l'Homme et la Loi Naturelle. New York: Maison Francaise.

Martínez, A. (1995). Diccionario Jurídico Básico. Buenos Aires: Heliasta.

Meléndez M. (2005). Implicaciones éticas de la muerte cerebral y los trasplantes de órganos. Revista Cubana de Investigaciones Biomédicas, 24 (1), 60-83.

Muriá, I. (2000). La concepción religiosa de la muerte. Un estudio evolutivo. Revista Digital, 1 (1). Disponible en: http://www.revista.unam.mx/vol.1/art2/.

Nava, G. J. (2012). Doctrina y Filosofía de los Derechos Humanos: Definición, Principios, Características y Clasificaciones. Razón y Palabra. Disponible en: http:// www.redalyc.org/articulo.oa?id $=199524700001$.

Nogueira, H. (2003). Teoría y Dogmática de los Derechos Fundamentales. México, D.F. Universidad Nacional Autónoma de México.

Núñez, S. (2006). Clasificación de los Derechos Humanos. Revista Digital Doctrina de la Universidad Autónoma Metropolitana, 1, 98-134.

Pérez Luño, A. (2003). Derechos humanos, Estado de Derecho y Constitución. Madrid: Tecnos.

Pfeiffer, M. L. (2006). El trasplante de órganos: valores y derechos humanos. Revista Persona y bioética, 10 (27), 18-46.

Rodríguez Blanco, M. (2015). Régimen Jurídico de cementerios y sepulturas. Granada: Comares.

Russo, E. (2001). Derechos y garantías. El Derecho al mañana. Buenos Aires: Editorial Universitaria de Buenos Aires.

Serani, A. (1999). La muerte encefálica y la determinación práctica de la muerte: Otra opinión disidente. Cuadernos de Bioética, 42, 36-62.

Tambussi, C. (2005). Perspectiva Histórica: Los Derechos Humanos y la lucha por los Derechos. En A. Gordillo, A. (ed.). Derechos Humanos (pp. 21-60). Buenos Aires: Fundación de Derecho Administrativo.

Vasak, K. (1984). Las dimensiones internacionales de los derechos humanos. Barcelona: Serbal.

Veizaga, K. (2005). Representación social de la muerte en distintas religiones. Revista Ajayu, 2, 6-32.

Volio, F. (1978). Algunas tipologías de Derechos Humanos. Costa Rica: Universidad de Costa Rica.

Worden, W. (1997). Tratamiento del duelo: asesoramiento psicológico y terapia. Buenos Aires: Paidós.

Yoffe, L. (1998). El duelo por la muerte de un ser querido: creencias culturales y espirituales. Buenos Aires: Plus Ultra. 


\section{LEGISLACIÓN CONSULTADA}

Convención Universal de Derechos Humanos.

Convenios de Ginebra de 12 de agosto de 1949.

Constitución Política de Colombia, actualizada con los Actos Legislativos a 2015.

Edición especial preparada por la Corte Constitucional, recuperada de: https:// bit.ly/2Hy7vhq (consultado: 23/5/2016).

Corán, recuperado de http://www.nurelislam.com/coran/index.htm (consultado: 4/3/2016).

Decreto 1333 de 1986 de la República de Colombia, por el cual se expide el Código de Régimen Municipal.

Decreto 056/2013 de 13 de diciembre de 2013, "Ordenanza de Cementerios», modificado por los Decretos 026/2014 y 001/2015 de Uruguay.

Gaceta Oficial 40.358, del 19 de febrero de 2014, Ley para la Regulación y Control de la Prestación del Servicio Funerario y Cementerios, de Venezuela.

Ley 133 de 23 de mayo de 1994 de Colombia.

Ley 258 de 15 de septiembre de 2012, «Ley de Servicios Funerarios de Puerto Rico». Ley 357, «Reglamento General de Cementerios» de 15 de mayo de 1970 de Chile.

Reglamento de Cementerios del Distrito Federal de los Estados Unidos Mexicanos de 20 de diciembre de 1984.

Santa Biblia (1998). Versión Reina Valera Revisada en 1960, Estados Unidos de América: Sociedades Bíblicas Unidas, p. 171.

\section{SENTENCIAS CONSULTADAS}

Caso Neira Alegría y Otros: Serie C No. 20. Sentencia de 19 de enero de 1995. La condena del Estado por la desproporción en el uso de la fuerza policial.

Comentarios de la propia Sentencia T-741/14 de 8 de octubre de 2014, de la Corte Constitucional de Colombia.

Comentarios de Sentencia T-0741/14 de 8 de octubre de 2014.

Comentarios de Sentencia T-741/14 de 8 de octubre de 2014.

Comentarios de Sentencia T-741/14 de 8 de octubre de 2014.

Caso Bámaca Velásquez: Serie C No. 70. Sentencia de 25 de noviembre de 2000. La condena del Estado por la falta de respeto a los restos mortales de las víctimas. Voto concurrente del juez A. A. Cançado Trindade. Sentencia de 14 de marzo de 2001.

Sentencia de la Audiencia Provincial de Burgos de 17 de enero de 2000,

Sentencia T-0741-14 - Derechos a la libertad de cultos y a la libertad de conciencia. Traslado, exhumación e inhumación de cadáveres. 